\begin{tabular}{|l|l|l|}
\hline Revista & Revista Latina de Sociología (RELASO) \\
Latina & Vol. 9, núm 1 (2019), pp. 31-49 \\
ISSN-e 2253-6469 \\
DOI: https://doi.org/10.17979/relaso.2019.9.1.2018
\end{tabular}

\title{
Violencia contra las mujeres, un análisis desde los imaginarios del cuerpo femenino
}

\section{Violence against women and female \\ body stereotypes}

Elizabeth Ballen Guachetá

Benemérita Universidad Autónoma de Puebla (BUAP), México https://orcid.org/0000-0003-1146-7258 ballen.elizabeth@gmail.com

Recibido: 11/04/2017

Aceptado: 01/06/2019

\section{Resumen}

Analizar cómo la violencia derivada de la guerra, de la delincuencia organizada y, en general, del sistema de dominación patriarcal marca el cuerpo de las mujeres, constituye un reto para la sociología pues implica posicionarlo como objeto de estudio en un contexto cultural y socioeconómico sumamente complejo ya que se caracteriza por la cosificación del mismo en cuanto territorio de satisfacción sexual masculina y lugar donde se venga el honor de los señores de la guerra. Los significados que la cultura ha impreso en los cuerpos femeninos han configurado una cartografía histórica y capitalista-patriarcal de la violencia hacia las mujeres, debido a las relaciones de poder que se han tejido en el conflicto armado, en el narcotráfico y al interior de las familias. Para comprender el cada vez más creciente fenómeno de la violencia contra las mujeres, en general, y el feminicidio, en particular, se analizan los imaginarios colectivos que circulan y legitiman las creencias acerca de la inferioridad, precarización y vulnerabilidad de las mujeres, a lo cual corresponde un modelo hegemónico dicotómico superior, con fuerza y con poder y que por lo tanto domina.

Palabras clave: Mujeres; violencia; símbolos; significados; contenidos; territorio; imaginario. 


\begin{abstract}
The study of how women's bodies are marked by the violence of war, organised crime and the patriarchal system of domination in general represents a challenge for sociologists since they must attempt to position the female body as an object of study within a highly complex cultural and socioeconomic context. Women's bodies are reified as a territory of male sexual satisfaction and a place where warlords avenge their honour. The meanings that culture has imprinted on the female body are a cartography of historical capitalist-patriarchal violence against women and the always gendered relations of power found in armed conflict, in the drug-trafficking trade and within families. To understand the growing phenomenon of violence against women, and femicide in particular, this study analyses the collective stereotypes of the female body that promote and legitimise the hegemonic dichotomous view of women as inferior, precarious, vulnerable and dominated by a stronger, more powerful male superior.
\end{abstract}

\title{
Keywords
}

Women; violence; symbols; meanings; contents; territory; stereotypes 


\section{Introducción}

En países que han padecido un conflicto armado interno, las mujeres han sido violentadas debido a las condiciones culturales que las han colocado como botines de guerra y territorios donde se venga el honor de los actores de la guerra. Ellas constituyen una población desplazada pues tienen que huir de las balas protegiendo a sus hijos y tratando de encontrar donde vivir y trabajar. Desafortunadamente, siempre se encuentran expuestas, en sus trayectos, a ser violadas por soldados, militares, guerrilleros, paramilitares, delincuentes comunes y coyotes que les cobran por pasar la frontera México-Estados Unidos; de manera que la violación es la peor arma de guerra que puede existir en todas las culturas.

En el marco de la sociología comprensiva de Weber, el cuerpo es tomado, entonces, como tipo ideal, es decir, como herramienta de análisis y reflexión sociológica sobre la corporeidad femenina, sus símbolos y significantes, para lo cual se parte del concepto del cuerpo como objeto material cuya función es servir de medio para que el yo (femenino o masculino) entre en interacción directa con la ecología cultural. De este modo, a la sociología le corresponde explicar la territorialización de esos significantes de la corporeidad femenina, a partir de un conjunto de sistemas simbólicos y representativos de un orden social llamado sistema patriarcal.

También, el análisis sociológico se enfoca en comprender las acciones discriminatorias, de odio y desprecio como consecuencia de la cosificación del cuerpo femenino, cuyo origen está en el micro espacio cotidiano de la familia donde se forma y socializa en el antagonismo entre masculinidades y feminidades; es decir, en prácticas, normas y valores culturales atravesados por el honor, el poder y el control de orden heteropatriarcal. Y es que en todas las culturas, los hombres han hecho un contrato social -acuerdos racionales- para determinar cómo circular las mujeres entre ellos, sin contar con ellas como sujetas (actoras) sociales con voluntad y autonomía. Esto tiene su fundamento en la obra Las estructuras elementales del parentesco, del antropólogo francés Claude Lévy-Strauss (1981), en la cual el argumento central es la prohibición del incesto. Al ser éste trasladado al campo antropológico-estructural del análisis feminista de Carol Pateman y Luce Irigaray, con respecto al origen de la cultura patriarcal en las organizaciones sociales primitivas, se puede advertir el intercambio de mujeres para los fines establecidos por los hombres tanto en lo económico como en lo político y lo individual.

Histórica y estructuralmente, lo anterior emerge de un esencialismo biológico que enmarca el rol femenino en la reproducción, el cuidado y la nutrición, comprobando, una vez más, el control y coerción que ejerce el sistema de dominación patriarcal sobre el cuerpo y la sexualidad femeninas. Del mismo modo, dada la configuración fisiológica de hombres y mujeres, la división social del trabajo coloca a las mujeres en el espacio privado del hogar en referencia con ese otro masculino, protagonista en el espacio público de la economía, del conocimiento, la política, la ciencia... lo cual lo convierte en proveedor y señor. Una aproximación a la respuesta de la pregunta ¿qué hace a las mujeres inferiores a los hombres, vulnerables a la violencia simbólica y física? es el lugar que ocupan en el sistema de producción capitalista pues lo doméstico no es valorado ni social ni económicamente. La reflexión

es entonces: las estadísticas muestran una creciente matrícula femenina en educación superior, cada vez hay más mujeres profesionales con ingresos socioeconómicos 
medios, también son más las proveedoras del hogar, lo cual indica que salieron al espacio público que era exclusivo de los hombres, luego entonces el patriarcalismo cobra la factura a las mujeres por lograr la independencia económica y el control sobre su sexualidad para la reproducción, lo cual transformó la estructura de las familias al tener a lo sumo dos hijos; en consecuencia, cada vez son más visibles las mujeres víctimas de violencia y feminicidio.

\section{La sexualidad femenina objeto de un contrato social}

Pateman en su obra, El contrato sexual (1995), habla de un contrato originario, como pacto sexual-social, en el cual el derecho politico es patriarcal; es decir, el poder que los varones ejercen sobre el cuerpo de las mujeres. Luce Irigaray en su obra Ese sexo que no es uno (2009), conduce a un plano mucho más pragmático y circunscrito a la realidad de violencia imperante en sociedades con conflicto armado interno, exacerbación de la delincuencia organizada y narcotráfico: "la mujer no es, en este imaginario sexual, más que soporte, más o menos complaciente, para la actuación de los fantasmas del hombre" (p. 18). Así, el cuerpo de las mujeres está fragmentado y jerarquizado en orden biológico-sexual, según represente la figura de la maternidad: el útero como recipiente de la semilla del varón y donde se gesta la vida; el pecho con su función de nutrición, de contacto físico, de calor; los glúteos como espacio de satisfacción erótica del varón.

Bernal (2013) hace un análisis de la mujer-objeto de intercambios en las sociedades primitivas, a partir del análisis feminista de Pateman e Irigaray: El derecho político conserva el derecho sexual o conyugal de los hombres sobre las mujeres. De modo que, el patriarcalismo no se suprime, por el contrario, se reafirma mediante un contrato social. Por su parte, la feminista belga, Luce Irigaray, afirma que el intercambio de mujeres en las sociedades primitivas (descrito por el antropólogo Lévi Strauss en su texto Las estructuras elementales de parentesco) expone el germen de la mujer-mercancia, quien circula en su valor de uso en tanto cuerpo reproductor, y en su valor de cambio en cuanto objeto de fetichización. La autora precisa que "en esas sociedades opera una economía en la cual se favorece a los hombres-productoresdueños de los intercambios, mientras que las mujeres se convierten en objetosmercancías de los mismos" (p. 145).

La corporeidad puede entenderse como el conjunto de cuerpos vividos por hombres y mujeres en un contexto cultural regido por leyes, costumbres, usos, valores y creencias determinados. La sociología la define como "un fenómeno social y cultural, materia simbólica, objeto de representaciones y de imaginarios" (Le Breton, 2002, p.7). Del mismo modo, es la representación colectiva de la red de relaciones y acciones, desde las más elementales a las más complejas, que tejen los cuerpos en los diferentes espacios cotidianos. La violencia es, precisamente, una de las relaciones y acciones que entablan los cuerpos en un contexto cultural de sometimiento, vulnerabilidad, dominación y asimetría en las relaciones de género.

El cuerpo como objeto material, a través del cual se entra en contacto con el medio ambiente, propicia la percepción y la experiencia a partir de los sentidos -ver, oír, sentir, oler, tocar-, lo cual constituye el pilar de la construcción de significaciones y contenidos del mundo, la vida, la realidad y la cultura. Entonces "la existencia es una experiencia empírica a través del cuerpo, de modo que es, en primer término, corporal" (Le Breton, 2002, p. 4). Descartes con su célebre frase "Pienso luego existo" centró la máxima importancia del ser en el pensamiento; es decir, en lo inmaterial, 
trascendental y eterno. De modo que es posible existir sin cuerpo ya que el pensamiento trasciende sus limites materiales y objetivos. De ahí la expresión que reivindica a los grandes ideólogos políticos víctimas de magnicidio: "A los hombres los pueden matar pero a las ideas no". Retomando a John Locke, el cogito -mente humana- es como un papel en el cual se escribe la experiencia, y ésta es producto del contacto del cuerpo con el entorno.

En este trabajo se defiende la postura objetiva, material, empírica y experiencial del cuerpo, en especial el de las mujeres. Desde la fenomenología, el análisis del feminicidio se fundamenta en el enfoque del cuerpo vivido de la filosofia merleaupontiana, basada en la experiencia del mundo de la vida, asunto que requiere especial atención y profundidad. En este sentido, el cuerpo es el territorio en el cual la cultura imprime significados y contenidos. Los cuerpos recitan esos significados dependiendo los roles, los estatus, el género, la clase social, la etnia; en momentos y contextos determinados. Los cuerpos de mujeres y hombres al relacionarse de manera asimétrica, mediada por el poder y la jerarquización social pueden llegar a la abyección del cuerpo femenino. Como diría Julia Kristeva (2003) es "protesta muda del síntoma, violencia estrepitosa de una convulsión, sin poder ni querer integrarse para responder, eso reacciona, esos abreacciona, eso abyecto" (p. 7). La abyección es, entonces, una subversión a la ley del padre que busca rescatar el cuerpo materno. Lo anterior fundamenta de alguna manera que la construcción de la corporeidad es el significante y el cuerpo es el significado; pero, a la vez la primera y el segundo son producto social y cultural; se retroalimentan continuamente para perdurar y transformarse a lo largo de la evolución humana, configurándose como todo un orden simbólico.

De tal manera, las mujeres viven su cuerpo femenino con unos significados específicos cuyo origen biológico (objetos materiales) las reduce a la reproducción de la vida, cuidar y nutrir ese nuevo cuerpo para que sea útil al sistema capitalista patriarcal. Es precisamente aquí donde se establece la diferencia como significado de ese cuerpo destinado a la procreación pues, debido a la división sexual del trabajo, el cuerpo de los hombres fue concebido como fuerte y apto para el trabajo, quedando en ellos el rol de proveedores económicos, junto con la construcción de conocimiento y de progreso. Ellas quedaron circunscritas al espacio privado del hogar cumpliendo el rol doméstico, no remunerado ni reconocido socialmente. Esta división sexual del trabajo es la que hace más profunda la diferencia y desigualdad entre hombres y mujeres, legitimando y naturalizando las relaciones de poder. Por ejemplo, los antiguos griegos pensaban que los hombres eran quienes daban a luz una nueva vida, a través del cuerpo de las mujeres, el cual no era más que un recipiente donde ellos depositaban la semilla. Asi, desde la antigüedad, aquel ya era producto de una cosificación simbólica, de ahí que sea un objeto al que se puede desechar pues es simplemente una cosa que una vez cumple su función, se bota.

Le Breton (2002) cuando define el cuerpo como ese objeto material modelado por el contexto socio-cultural, a manera de escenario en el cual el actor o actora sociales recitan un guion, "es ese vector semántico por medio del cual se construye la evidencia de la relación con el mundo" (p.7), y siempre está atravesado por la sexualidad pues resulta imposible concebir el cuerpo sin significados sexuales inscritos en su identidad y comportamiento para su aceptación social. Al respecto, Judith Butler (2001) define el sexo asociado al concepto del cuerpo: "el sexo como materia, el sexo-como-instrumento-de significación-cultural, es una formación discursiva que funciona como un fundamento naturalizado para la distinción naturaleza/cultura y las estrategias de dominación que esa distinción apoya (p.71).

En efecto, el sistema binario cultura-naturaleza está asociado a las categorias 
masculinidad-feminidad en cuanto que la cultura dicta significados y contenidos a la naturaleza, convirtiéndose esta última en lo "otro", legitimando mediante la praxis cotidiana los ideales del significante y el sistema de significación que reproduce la estructura de dominación. De este modo, las dicotomías cuerpo-mente, culturanaturaleza, sexo-género están atravesadas por relaciones de poder que colocan a la naturaleza, la subjetividad y el sentimiento como femenino y, a la cultura, como la mente, la razón, la lógica, la objetividad y la capacidad de acción que son características masculinas. Así, lo femenino es un agente pasivo en espera de un sujeto masculino que le dé significación y existencia cultural y social, a través, generalmente, de la maternidad y de la institución civil y religiosa del matrimonio.

¿Qué sucede entonces con el cuerpo victimizado de las mujeres, en cuanto son despojados de valor y dignidad humana, "es un delito cometido por odio a la feminidad, se asesina a la mujer por el simple hecho de serlo" (Caputi y Russell 2006). $\mathrm{Al}$ hacerse tan recurrente, la muerte violenta de varias mujeres, queda al descubierto una sociedad y una cultura misógina donde las identidades se construyen de manera no solo opuesta sino antagónica, cuyas raíces se encuentran en la conformación histórica del sistema patriarcal como infraestructura y superestructura del gran edificio social. El patriarcado y el modo de producción capitalista son variables dependientes que se retroalimentan para mantener el rol de la mujer como reproductora y cuidadora de la fuerza de trabajo, y del lugar que ocupa en el sistema de producción. Del mismo modo, las instituciones políticas, educativas, religiosas, mediáticas y la familia construyen y legitiman ideologías que colocan al ser masculino en el centro de la organización social y a la mujer como satélite que gira alrededor de él. De ahí, la existencia de la misoginia y la homofobia como posturas que expresan el odio a la feminidad y promueven el desprecio por el ser y vivir el cuerpo de mujer. Al respecto Julia Kristeva (1987) dice:

La abyección de si sería la forma culminante de esta experiencia del sujeto a quien ha sido develado que todos sus objetos solo se basan sobre la perdida inaugural fundante de su propio ser, la separación de un comienzo aparentemente blanco para tomar forma en el juego simbólico al que llega (p.12).

Se trata de reducir ese cuerpo de mujer a nada, a un objeto sin valor, despojarlo de lo humano para abyectarlo, desecharlo, botarlo a la basura, destruirlo desaparecerlo. Al observar las imágenes fotográficas de las notas de prensa sobre feminicidio, los cuerpos de las mujeres están desnudos o semidesnudos, abandonados en terrenos baldios o sobre la orilla de una carretera, en la ribera de un río, en bolsas de basura o costales, enlodados, desarticulados como una muñeca vieja, mutilados por los perros hambrientos, los buitres y las moscas. Parafraseando a Pérez y Larrondo (2016), la asimetría social y cultural entre sujetos masculinos y objetos femeninos convierte el cuerpo de las mujeres en utilizable, desechable, que se maltrata, se denigra o se deshecha porque es reemplazable.

Estas formas tan crueles de acabar con la vida de una mujer, van más allá, pues son métodos que el sistema capitalista patriarcal utiliza para el control y domesticación de las mujeres. Como dice Rita Segato (2013) "el feminicidio está inscrito en la pedagogía de la crueldad, en torno al cual gravita todo el edificio de poder" (p. 56), pues el asesinato violento contra una mujer es el mensaje que envía el varón, y todo el sistema en el que se sostiene esta ideología, al resto de las mujeres para afirmar a quién pertenece el mundo. 


\section{El cuerpo de las mujeres como territorio a ser conquistado}

La analogía que relaciona el cuerpo de las mujeres con un territorio a ser invadido o conquistado ha sido empleada, a manera de reflexión, por las feministas colombianas cuando analizan la situación de las mujeres en el conflicto armado. Así, Segovia y Nates (2011) sostienen que la violencia no es un estado sino un lugar. E1 estado de violencia presupone que hay naciones condenadas a vivir y hundirse en ella, lo cual conduce a estereotipos que, a su vez, generan más conflicto, pues son estigmatizadas como violentas. Es el caso de Colombia y México entre otros países de América Latina y Africa.

Para hablar del cuerpo de las mujeres como territorio cartográfico de la violencia es necesario diferenciar entre varias clases de la misma, de acuerdo con criterios como la "configuración y sentido desde dónde y cómo se producen, qué implican y qué buscan...." (Segovia y Nates, 2011, p.13). Para responder a estas preguntas se parte del concepto de identidad, el cual se construye sobre tres principios: solidaridad, reciprocidad y cohesión. La identidad, parafraseando a las autoras, se configura a partir del lenguaje verbal, la forma de interacción, el lenguaje corporal, la existencia o ausencia, las prácticas sociales cotidianas, la trayectoria histórica, el lugar que hombres y mujeres ocupan en el espacio físico y social. Todo esto define la otredad, la mismidad y la alteridad. De manera que cuando un país se torna violento es porque hay una crisis multifactorial reflejada en desarmonia, aflicción y descomposición.

El cuerpo de las mujeres como territorio a ser colonizado en un contexto de conflicto armado, como el de Colombia o Liberia, dadas las proporciones y características específicas de su confrontación bélica, responde a la organización identitaria de grupos beligerantes con una ideología, de izquierda antagónica al gobierno legítimo, que busca un país más justo y equitativo; o conseguir el poder a cualquier precio junto con el control sobre las finanzas y los recursos naturales. Es necesario resaltar que el poder es masculino al igual que las finanzas y la guerra, mientras que los recursos naturales, producto de la tierra, son femeninos, éstos han sido expropiados con violencia para el enriquecimiento y concentración de poder de las naciones industrializadas y ricas gobernadas por célebres patriarcas.

En el caso de Colombia, según Segovia y Nates (2011), "la rebelión se considera a sí misma como una guerra justa. El problema reside en saber cuál es la causa justa de la guerra y lo justo mismo" (p.14). En el otro extremo están los grupos paramilitares (ultra derecha), entrenada y armada por el ejército y las fuerzas militares del Estado, para combatir a la guerrilla y proteger la propiedad privada de una clase con poder político y económico. Obviamente esto se hace de manera oculta y se cobra por los organismos de Derechos Humanos nacionales e internacionales. También se crean las autodefensas, pues las comunidades se organizan y se arman para hacer justicia por su propia mano, ante la situación de ciudadanos indemnes, pues el Estado no los protege ni hace justicia. Están los carteles del narcotráfico que se unen con la guerrilla para desestabilizar aún más al gobierno y a la elite política. Hay demasiado dinero para comprar y corromper funcionarios e instituciones. En este panorama, las mujeres circulan como territorios apropiados, invadidos o conquistados por alguno de estos grupos: guerrilla, paramilitares, narcotraficantes, ejército, fuerzas militares, todos armados al margen o dentro de la ley. Así, una mujer que atiende un quiosco de tinto (café) y lo vende a un guerrillero es sacrificada por los paramilitares pues esto constituye para ellos una traición a la lucha por un "estado justo". Había mujeres que tenían un hijo de un guerrillero y uno de un paramilitar y esto se lo cobraban tanto los 
unos como los otros marcando su cuerpo: "Este cuerpo es de la guerrilla o este cuerpo pertenece a los paramilitares". Por esto, el hecho de extraer el feto del cuerpo de una mujer era exhibido públicamente como ejemplo de lo que le puede suceder a otras si se relacionan con el enemigo. El análisis de esta acción simbólica se sitúa en el útero que habita en el cuerpo de una mujer y en el cual se origina la vida.

Un análisis analógico de la extracción del feto puede significar, semiológicamente en la cultura Wayuu -ubicada en la Guajira colombiana- que el cuerpo de la mujer debe ser cerrado para que no entre el mal; es decir, que el enemigo no se reproduzca. El espíritu Wanülü ataca el cuerpo, lo usa para doblegar el espíritu y captar almas para su propio grupo identitario, lo cual pone en peligro la sociedad. "El cuerpo, al permanecer abierto al mal, se convierte, diria Mary Douglas, citada por Segovia (2011) en una frontera precaria y amenazada que debe superarse" (p.55). De manera que los paramilitares evitan que se reproduzcan los guerrilleros que desestabilizan la nación al pretender cambiar el orden político y económico.

Cada grupo identitario marca su territorio: la guerrilla está en la selva; los paramilitares en los departamentos del norte del país, donde existieron grandes haciendas de terratenientes que importaban y exportaban ganado pero que fueron "vacunados" por la guerrilla y tuvieron que huir para salvar sus vidas; los narcos están en las selvas donde se encuentran los cultivos y funcionan los laboratorios clandestinos de producción de cocaína; las autodefensas son propietarios de tierras que se organizan para auto protegerse ante la impotencia, la ausencia y desprotección del Estado.

Otro ejemplo es Liberia en Africa. Alli mujeres cristianas y musulmanas se unieron para derrocar al dictador Charles Taylor quien tenía un ejército, para defenderse a sí mismo, conformado por niños de 9 a 15 años. La guerra tuvo tres detonantes: el control sobre los recursos naturales (diamantes), mantener la desigualdad entre ricos y pobres y el odio entre etnias. Asatu Bah Kenneth, subdirectora de la Policía Nacional Liberiana, quien organizó a las musulmanas para que se unieran con las cristianas, sostiene que el ejército rebelde se llevaba por la fuerza a chicos que se encontraban en sus casas, los drogaban y les daban armas. Asatu cuenta también que los entrenaban para que tomaran todo lo que encontraran a su paso. Un niño de 9 años dice orgulloso y con una amplia sonrisa de satisfacción: "ayer maté a tres enemigos". La lidereza de la Iniciativa de Paz de Mujeres Cristianas, Leimah Gbowee, cuenta que para evitar que sus esposos se fueran a engrosar las filas del ejército rebelde y lograr que se unieran a ellas para negociar la paz, les negaban el sexo. En Colombia las mujeres organizadas para conseguir la paz, también incurrieron en esta práctica y le llamaron a su protesta: "Huelga de piernas cruzadas".

Una mujer liberiana narra pausadamente lo siguiente: Conocí a una mujer en un campo de desplazados. Y...dijo que el día que los rebeldes atacaron la aldea, ella, sus hijos y su esposo, estaban como cualquier otro día. Y cuando llegaron, arrestaron al esposo, le dijeron que se acostará de espalda en el suelo. Él se acostó. Y su hija que, entonces, tenía 12 años, había comenzado a menstruar, la tomaron y le dijeron: tírate en el suelo y súbete el vestido. Y ella dijo que vio a un soldado sacar un largo cuchillo y decirle: mujer, ponte de pie, canta, aplaude y baila, y ella comenzó a cantar, aplaudir y bailar. Ellos le dijeron: mírame bien, si desvias la mirada mataré a tu esposo. Primero date la vuelta. Ella dijo que cuando se dio vuelta, vio a esos tipos enormes, uno se desnudó para violar a su hija en su presencia (la narradora cierra los ojos con el dolor del recuerdo y exclama un suspiro). En ese momento, ella estaba en medio con su esposo, de un lado, y su hija, del otro, ambos con la cara hacia el sol (la narradora levanta las manos señalando hacia arriba con una inmensa expresión de dolor y 
continua hablando lentamente) y le dijeron: mira a tu derecha, ella miró, gradualmente le estaban cortando el cuello a su esposo -hace énfasis: igradualmente!- y le gritaban: ¡canta! y ella cuando vio la sangre de su marido brillar en el piso, se desmayó. No sabía dónde estaba. El día que la conocí aún seguía entonando la canción que le exigieron que cantara, y aplaudiendo y bailando. Y por la violación su hija quedó embarazada (la narradora concluye con la mirada perdida en la distancia y un largo suspiro de impotencia: ¡Ufff!...Hmmm).

La lider de Iniciativa de Paz de Mujeres Cristianas, Leimah Gbowee, recuerda que cuando se plantaron frente al hotel donde estaban negociando la paz, la iban a arrestar por obstruir la justicia. Ella furiosa exclamó: “¿obstruir la justicia? Me puse como loca y les dije: les voy a hacer muy sencillo para ustedes que me arresten: jvoy a desnudarme!". Otra mujer de la organización agregó: "imaginense la dimensión de la protesta de Leimah, es una vergüenza muy grande para cualquier liberiano ver a su madre desnuda en público".

En todas las culturas, la moral es un valor femenino que debe ser promovido y resguardado. Adquiere un significado social en relación directa con el uso que las mujeres hacen de su cuerpo en cuanto ente sexual. Celia Amorós (2000) dice que se han exaltado los valores femeninos positivos como la ternura, la suavidad, la abnegación; en contraposición a los valores de competencia, fortaleza y rendimiento, universalizados como valores masculinos. En México, Colombia y tantos otros países, marianos por excelencia, el discurso religioso resalta las virtudes de la virginidad, la familia como principio y fin de la organización social, la maternidad como realización plena de las mujeres, el ser una buena madre, abnegada, sacrificada, víctima, sufriente. La religiosidad en estos países del continente americano refuerzan la moral femenina de la que nos habla Amorós. Se necesita reproducir estos valores femeninos para mantener el control social a través de un discurso religioso que exalta el modelo de la Virgen María.

Como cultura patriarcal, el código de honor hace parte de un pacto ético en el cual guerrilleros, paramilitares, ejércitos, narcotraficantes, proxenetas, acuerdan la posesión de las mujeres, o, mejor dicho, sus cuerpos, entre ellos. De ahí que el honor entre enemigos se vengue en el cuerpo de sus mujeres; por eso son violadas, torturadas, explotadas sexualmente y marcadas como propiedad privada. Entre grupos que se disputan el poder, la preñez tiene un significado político, pues ese nuevo ser va a ser un militante más para "la causa" o un enemigo que debe ser eliminado. Por ejemplo, en México, ocurrió la matanza en Acteal en el estado de Chiapas, el 22 de diciembre de 1997. Paramilitares atacaron la población indefensa, desarmada pero en resistencia, haciendo ayuno y oración en una capilla. Según el sitio web de la sociedad civil llamada Las abejas de Acteal: "El ataque fue perpetrado por alrededor de 90 personas, según refieren testigos oculares, y el hecho de que un puesto de operaciones mixtas (fuerza militar, judicial y de seguridad pública) se encontrara asentado a 200 metros, ha servido para justificar las opiniones que apuntan hacia una responsabilidad directa del estado mexicano". La masacre se ensañó especialmente con las mujeres embarazadas, abriéndoles el vientre para arrancar al producto de sus entrañas. De igual modo, los feminicidios de Ciudad Juárez, tenían características relacionadas con la sexualidad femenina, pues algunos cuerpos fueron encontrados con marcas como que los pezones eran arrancados a mordiscos. Según la página web: Nuestras hijas de regreso a casa "los cuerpos sin vida mostraban evidencias claras de haber sido brutalmente torturadas y asesinadas, violadas de manera tumultuaria $\mathrm{y}$ arrancadas partes de su cuerpo o quemadas".

El cuerpo de las mujeres es un territorio que representa la cartografia de la 
violencia porque es estéticamente bello y cotizado entre los hombres que tienen dinero pues los lucen públicamente para ser admirados. Se trata de un cuerpo adorno que se muestra al igual que un automóvil deportivo. Un narco puede conseguir la mujer que quiera y su cuerpo es todo un despliegue de lujos, joyas, ropa, accesorios, peinados, cirugias estéticas; pero es también donde predomina el temor a perder la vida y a soportar el control, el cautiverio, el dolor de las relaciones sexuales forzadas, la tortura, la muerte, todo lo cual significa desencuentros, conflictos y rupturas. Una aproximación desde la fenomenología sociológica, acerca de lo que significa vivir el propio cuerpo, es darse cuenta que éste es estética, armonía, encuentro, vida pero también es sometimiento, esclavitud, vulnerabilidad, debilidad, enfermedad y muerte.

\section{Mujeres, bienes simbólicos en la economia masculina}

Judith Butler (2010) habla de precariedad y precaridad para demostrar la vulnerabilidad tanto de hombres como de mujeres a sufrir y morir por la propia naturaleza biológica; pero a esto se suma la condición social y cultural que acentúa las diferencias de clase y de género junto con la incapacidad del Estado de proteger a los grupos más débiles. La precariedad es el sentido de existencia, la condición ontológica de todo ser vivo. Se vive en precariedad porque se es mortal y vulnerable. La precaridad se refiere a la resolución de necesidades políticas, económicas, sociales y de subsistencia. Quienes no las resuelven viven en un frágil estado de precariedad. Los seres humanos, en general, padecen la precaridad dadas las condiciones de escasez de empleo y oportunidades para tener calidad de vida. La población femenina, la niñez y los adultos mayores la viven con mayor intensidad, más aún cuando se encuentran en un contexto violento y de conflicto armado. En este sentido Butler habla de la ontología del cuerpo, el "ser" del cuerpo, un ser siempre al servicio de los demás, dependiente de normas, organizaciones sociales y politicas "que se han desarrollado históricamente con el fin de maximizar la precariedad para unos y minimizarla para otros" (Butler, 2010 , p.15). Así, el cuerpo es modelado socialmente y, precisamente por eso produce significados ontológicos en la estructura social. Entonces, el imaginario colectivo que se tiene sobre el cuerpo de las mujeres es que es un territorio a ser conquistado con violencia, a ser intercambiado como mercancía con valor de uso y valor de cambio, a ser destruido y botado a la basura.

En Colombia, las mujeres constituyen uno de los grupos más vulnerables y precarizados. Ellas se han organizado y movilizado para exigir entrar en las negociaciones del proceso de paz y han logrado que el Estado implemente el Plan Nacional de Acción para aplicar la resolución 1325 (2000) de las Naciones Unidas sobre Mujeres, paz y seguridad, con la cual se busca proteger a las mujeres en aquellos países que sufren un conflicto armado interno; pero también puede ser implementado en naciones que buscan mantener la paz. En Colombia, las mujeres sostienen que dan la vida y los hombres la quitan en la guerra; por lo tanto, ellas tienen la autoridad moral para negociar la paz, pues ¿Cómo promueven la paz quienes hacen la guerra? Así, la interpretación simbólica, de los cuerpos de las mujeres en actitud de resistencia ante la guerra, es que el cuerpo es un modelo que puede servir para representar cualquier frontera precaria o amenazada. El cuerpo es una estructura compleja (...). El cuerpo es un simbolo de la sociedad, y a considerar los poderes y peligros que se le atribuyen a la estructura social como si estuvieran reproducidos en pequeña escala en el cuerpo humano (Douglas, 1991, citado por Segovia, 2011, p.p.56-57).

En el caso mexicano, una investigación del antropólogo Juan Antonio Flores 
Martos (2011), en el Estado de Veracruz, sobre violencia hacia las mujeres, da cuenta del cuerpo femenino como un territorio sensible, una "carne en la que el varón puede dejar diferentes clases de marcas, más o menos indelebles, por motivos espurios o el mero deseo, placer o azar" (p.30). Un testimonio de una de las informantes de Flores es el siguiente:

Estando alli en el Bulevar, con la bebida y tomando, a mi amiga "se le subió el mar", y empezó a sentirse muy mareada, y él también estaba un poco mareado, y que mi amiga le besa y él se dejó no, y que se abrazan, y él que empieza ya con las manos y ella que no, parándoselas, y el que ya quería que se fueran al coche, entrarla en el coche, y ella que le dice que no, porque le daba mucha pena, porque su marido la había dejado marcada, tenía una marca. Su marido la trató como una prostituta, lo que hiso fue rasurarle ahí abajo, la mitad del mismo, y eso a ella la traumó, y tiene desde entonces mucho trauma, le da mucha vergüenza estar con un hombre. La pobre es una mujer marcada (Doña Mari). (Flores, 2011, p.30).

Al igual que Segovia cuando estudia la cultura Wuayuu, Flores (2011) estudia la posesión de los cuerpos femeninos por parte de los demonios. Son ellas las que se retuercen, emiten sonidos de ultratumba, vomitan y expulsan flujos debido a su "posesión" y su liberación espiritual:

La sujeción fisica que revelan las vendas con que son atadas a las bancas de la iglesia en Puentejula, remiten a otra clase de sujeción: la social, con reglas y fórmulas tan rígidas como esas ataduras, a las que de modo implícito y plástico se somete ante los ojos de Dios y de la comunidad (familiares y rezadores del rosario) a las "endemoniadas", personas con desórdenes que provienen de la ruptura o el alejamiento de alguna de esas normas, y que tras ese exorcismo colectivo vuelven a sentir recompuesto el contrato social previo. (P.29). (...) La hechicería se revela como un fenómeno de violencia simbólica -de agresión, pero también de defensa, una respuesta y canalización de la violencia de los subalternos frente a los poderosos que tienden a ostentar prácticamente el monopolio de la violencia-. Algunos de los "trabajos" narrados por agentes rituales de la ciencia espiritual, o por sus clientes, perfilan a la "brujería" como una respuesta defensiva eficaz a la agresión y dominación social (propietariostrabajadores, españoles-veracruzanos, varón-mujer), (p.36).

El cuerpo vivido de mujeres veracruzanas revela la violencia presente en el espacio doméstico, en las relaciones de pareja, en el micro contexto de la familia y del hogar convertido en el lugar de sufrimiento y sometimiento de la mujer. Flores (2011) comenta las emociones implícitas en su papel de investigador que realiza en un estudio etnográfico:

Más complicado me resultó acceder a otro tipo de conversaciones y discursos que consideraban la violación como una presencia urbana -aunque las páginas de la prensa local y los semanarios sensacionalistas ofrecen por sí solas un panorama detallado de la alta frecuencia de este delito en Veracruz-, así como una práctica existente entre ciertos segmentos de varones jóvenes, algunos de los juniors, de las personas conocidas de la ciudad, y en concreto de la colonia española en el Puerto (p.35). Dos de mis informantes, A. J. (26 años), y B. M. 
(30 años) me contaron cómo fueron objeto de una violación por juniors de familias españolas de estrato socioeconómico alto, coincidiendo ambas en que los agresores eran conocidos con los que tuvieron una cita, y que al ser acompañadas por ellos a su casa, fueron violadas en el automóvil. Ninguna los denunció, y continuaron viéndolos en la universidad a la que asistían, además de tener que contemplar sus fotografias sonrientes en las páginas de "Sociales" Ecos de Sociedad de la prensa local. (P.36).

En los carteles del tráfico de drogas, las mujeres son tatuadas -marcadas- con las iniciales de su "patrón" en los glúteos o en los senos y circulan como propiedad privada de los grandes capos. Ningún otro hombre puede poseerla sexualmente porque ella será asesinada y el honor de su dueño será vengado violando y/o asesinando a las hermanas o hijas de quien usufructuó ese territorio propiedad de un narco. De esto hay escalofriantes evidencias en la industria cultural sobre todo colombiana y mexicana como "las muñecas de la mafia", "El cartel de los sapos", "El señor de los cielos", "E1 infierno", "la promesa" "anónima", "El patrón", "Sin tetas no hay paraíso".

En la industria cultural mexicana y colombiana suele considerarse que una mujer que ha sido escogida por un narcotraficante, no puede negarse a pertenecerle y, una vez que entra a formar parte de su capital simbólico, como se posee un caballo árabe o un coche de colección, ella no puede salir de allí y si se involucra sentimental o sexualmente con otro hombre, pagará con su vida. Algo necesario de resaltar es que los narcotraficantes tienen muchas mujeres, son promiscuos, pero solo tienen hijos con sus esposas legítimas. Por ejemplo, en El Patrón del mal, Pablo Escobar cuando sabe que una de sus amantes está embarazada la manda privar de su libertad y el veterinario, encargado de cuidar sus caballos, le saca el bebé y ella muere. En El señor de los cielos, Casillas dispara directamente al útero de su amante embarazada. Esto indica que sus descendientes solo llegan por una vía reconocida, sagrada y legítima, no son producto de una aventura o de una relación paralela no reconocida social ni legitimamente. La esposa es el garante moral de su familia ante la sociedad, él puede ser un perverso delincuente, pero su esposa y sus hijos son intocables y sagrados. Este es un elemento común en las series de televisión y películas de cine que se alimentan de la realidad que acontece en nuestros países. La violencia más cruel y despiadada se vuelve material televisivo para telenovelas y series y su circulación en amplios públicos tiene una influencia muy grande en el imaginario colectivo. Es entonces cuando vemos cómo entre amplios grupos de la población está tan normalizada y naturalizada la violencia.

En Colombia la territorialización del cuerpo como botín de guerra hace evidente que se vea obligado a responder a los deseos de quienes lo poseen. En México la cuestión del narcotráfico no es diferente, es muy común escuchar a estudiantes universitarias decir que no van a tal o cual antro porque alli van narcos y si se fijan en ellas no podrán negarse a ser sus parejas. Una vez elegidas por ellos, les pertenecen de por vida.

Al respecto, Saskia Sassen (2010) en su obra, Una sociología de la globalización, argumenta que las ciudades son espacios donde se inscribe una cultura empresarial dominante, pero también es donde existe la multiplicidad de otras culturas e identidades; es decir, en todos los ámbitos urbanos circula una ideología modernizadora y globalizadora. Al analizar el cuerpo en el espacio urbano, los ideales para su liberalización que vienen de afuera, chocan con ideales tradicionales de la vigilancia y el control del mismo, herencia del virreinato español en América Latina. "La cosmovisión católica controla el cuerpo y la sexualidad, al punto de estar 
únicamente destinado a la procreación y coloca al matrimonio como la institución que valida y legitima las relaciones sexuales" (Collignon, 2010, p.105). Es en este contexto donde el cuerpo se ha convertido en una unidad de explotación física, sexual y mentalque se articulan problemas de reconocimiento a "otras" identidades, lo cual nos indica la necesidad de construir un nuevo significado a partir de estos cambios. Ello implica que en su re-significación, el cuerpo sea visto como un simple instrumento de comunicación, contacto y creación.

Pero ¿el cuerpo es tan solo un objeto instrumental? La semiótica de Barthes (2011) hace pensar que el cuerpo es algo más; es movimiento y por ende vida; tiene memoria y responde en ocasiones sin necesidad de tener consciencia ni razón del por qué. Para ello Barthes dice, con un ejemplo literario, que "el placer del texto es ese momento en que mi cuerpo comienza a seguir sus propias ideas, pues mi cuerpo no tiene las mismas ideas que yo". (Barthes, 2011, p.26).

El placer, el goce del cuerpo vivido debe ser aquel punto donde se rompe la naturalidad de la violencia estructural. Y este último punto tiene que ver con que el cuerpo de las mujeres realmente es un territorio rebelde, subversivo al dominio masculino, por lo que debe ser dominado y controlado. Un ejemplo más es el de las mujeres de San Salvador Atenco. Ellas denunciaron represión social y tortura sexual, por parte de las autoridades, al defender tierras ejidales que el gobierno deseaba expropiar para la construcción del nuevo aeropuerto de Ciudad de México (Guzmán, 2014, p.42). Con este caso se ejemplifica que la violencia más agresiva hacia las mujeres, en estos regímenes machistas, es penetrar el cuerpo y penetrar significa invadir, dominar, humillar, deshonrar. Las mujeres viven violencia, la naturalizan como parte de vivir su cuerpo porque así lo han aprendido de la cultura, de su hábitat social, de su familia: "Así nos toca a las mujeres", "Las mujeres venimos al mundo a sufrir".

\section{A manera de conclusión, Un análisis desde Bourdieu}

La realidad social es el objeto de estudio de la ciencia social y para comprender el fenómeno de la violencia contra las mujeres y el feminicidio se ubica el análisis en la percepción que tienen los actores en la misma; es decir, los puntos de vista, las creencias, las perspectivas que construyen dependiendo de la posición que ocupan en el espacio social objetivo. Esta es la sociología espontánea de Bourdieu. Para responder a la pregunta: ¿Cuáles han sido históricamente los imaginarios sobre el cuerpo femenino que han legitimado y "naturalizado" la violencia contra las mujeres, incluido el feminicidio, se retoman los conceptos de violencia simbólica y dominación masculina de Pierre Bourdieu. El primero se refiere a "esa violencia que arranca sumisiones que ni si quiera se perciben como tales apoyándose en unas expectativas colectivas, en unas creencias socialmente inculcadas" (Bourdieu, 1999, p. 173). Las mujeres han sido educadas para obedecer, ser dóciles, estar para los demás y ante todo ser aceptadas y queridas a costa de su felicidad y realización personal. De manera que la violencia simbólica la ejerce el dominador con la "aceptación" de la víctima dada la posición que ocupan en la estructura social y en el sistema productivo, con base en un esencialismo biológico que instituyó históricamente la división sexual y social del trabajo. Esto significa que en las sociedades tradicionales la dominación era personal y en las avanzadas corresponde a la clase social, la cual según Bourdieu -criticando a Marx por su reduccionismo económico- no puede definirse solamente desde las relaciones de producción económica, sino por los efectos sobre las prácticas de las relaciones que se tejen en la estructura social. Ver la clase social con un enfoque esencialmente objetivista implica desconocer "las luchas simbólicas que se disputan 
las representaciones legítimas del mundo social, la jerarquía en el interior de los campos y entre los campos" (Martinez, 2010, p.1). En este sentido, en una sociedad tan jerarquizada, el género masculino es el modelo hegemónico y dominante, mientras que las mujeres ocupan una posición muy baja en la estructura social, debido al rol doméstico que desempeñan en el espacio privado del hogar.

Para hacer efectiva la violencia simbólica es necesario un poder simbólico que

(...) es un poder legitimador que suscita el consenso tanto de los dominadores como de los dominados, un poder que construye mundo en cuanto supone la capacidad de imponer la visión legítima del mundo social y de sus divisiones y la capacidad de imponer los medios para comprender y adaptarse al mundo social mediante un sentido común que representa de modo disfrazado el poder económico y político, contribuyendo así a la reproducción intergeneracional de acuerdos sociales desigualitarios" (Fernández, 2005, p. 12).

De este modo, Bourdieu hace énfasis en que la dominación masculina nunca acabará porque los hombres no están dispuestos a negociar ni ceder sus privilegios de clase. Lo simbólico, aquello presente en los espacios en los cuales se tejen relaciones entre hombres y mujeres, toma identidad como objeto de autonomía dando lugar a relaciones simbólicas representadas en relaciones de poder o, lo que es lo mismo, el imaginario se traduce en representación social materializada en prácticas que se legitiman porque son interiorizadas y reproducidas colectivamente. Un ejemplo de esto es el gusto popular y el gusto burgués que estudia Bourdieu; en la industria cultural, específicamente en el melodrama televisivo Yo soy Bety la fea lo que la hace fea es la ropa que usa, los colores, los diseños de gusto populachesco, el peinado, los brackets, las gafas, la risa, el lenguaje verbal y corporal, la forma de caminar, de reir, de hablar, de dirigirse a sus superiores, todo lo cual recita el discurso de la clase social que la pone fuera del alcance del hombre objeto amado exitoso, dueño de su propia empresa, muy atractivo, que viste trajes de marca, materiales y diseño exclusivos, rodeado de mujeres hermosas y distinguidas, y en fin... el género está atravesado por la clase y la etnia, factores que determinan la vulnerabilidad a la violencia simbólica. El gusto burgués lo representan los dueños de Ecomoda pues mientras ellas y ellos van a comer a un restaurante francés, el cuartel de las feas (secretarias) van al "Corrientazo" y visten ropa ordinaria, su peinado es simple mientras que las empresarias tienen un estilista francés al que acuden periódicamente para cambiar el corte, el color, el peinado...Mientras las feas van a discotecas corrientes donde tocan música popular, los empresarios van a opera y a zarzuela.

Para Bourdieu existen dos formas de ejercer la violencia simbólica. Una es mediante el intercambio de dones -diferente de la postura de Marcel Mauss y leviStrauss basada en la reciprocidad- en el cual a través de un regalo se ejerce poder disfrazado de generosidad. Así, el amor romántico de las telenovelas y, en general, de la industria cultural (baladas, boleros, canciones) implica un intercambio de dones para construir una relación heterosexual que debe llegar a la institución matrimonio y familia. Estos dones van desde un chocolate hasta un anillo de compromiso de diamantes; desde luego, el amor romántico es capitalista pues del valor económico del don o regalo es el tamaño del amor que el dominador pone en juego para obtener el favor de su víctima. Un ejemplo de la psicología jungiana es el cuento de Barba Azul, en el cual este hombre corpulento y fuerte busca una esposa. Para conseguirla, organiza un día de campo con una madre que tiene tres hijas. Después de compartir 
con ellas y llenarlas de atenciones y regalos se da cuenta que la hija que le conviene como esposa es la menor pues las mayores lo ven con desconfianza. La hermana menor es muy joven, ingenua e inocente porque que le falta experiencia. Después de haber ganado a la madre con obsequios y cortesías, celebra la boda y lleva a su nueva esposa a vivir a su castillo el cual cuenta con muchas habitaciones. Un día le dice a ella que tiene que salir de viaje y que puede invitar a su familia a su nuevo hogar, preparar un gran banquete $\mathrm{y}$ hacer lo que quieran menos abrir una habitación prohibida. Le entrega un llavero con todas las llaves y le señala una que no debe usar bajo ninguna circunstancia. Cuando él se va, la joven esposa llama a sus hermanas y emprenden un juego en el cual deben encontrar la llave de cada puerta, la curiosidad las hace caer en la desobediencia y encuentran el cuarto prohibido. Cuando introducen la llave en la puerta comienza a sangrar. La menor de las hermanas trata por todos los medios de detener la sangre pero es imposible. De repente escucha que llega Barba Azul y rápidamente corre a esconder la llave sangrante entre la ropa de su armario. El se da cuenta que ha desobedecido y le dice que su castigo es la muerte. Ella le pide tiempo para despedirse de su familia pero la idea es esperar a que lleguen sus hermanos a salvarla. Pregunta varias veces a sus hermanas: ¿escucháis llegar a nuestros hermanos? Y responden que no hasta que al fin escuchan el galopar de los caballos entrando al castillo. Los hermanos matan a Barba Azul y logran salvar a la joven esposa de una muerte segura, como la de todas aquellas mujeres hechas esqueletos que hallaron en la habitación prohibida. Es necesario entender qué significa la llave sangrante, qué significan los hermanos que llegan a salvarla y qué significa abrir la puerta y ver aquello que la hace prohibida. En realidad tiene que ver con el acceso de las mujeres al conocimiento mediante la desobediencia pues en todas las culturas las mujeres han sido criadas para obedecer y atender a sus hombres (padres, hermanos, esposos, jefes). La religión, la educación, la familia controlan a las mujeres, sus cuerpos y su sexualidad mediante la negación de su acceso a conocer todo su potencial, han castrado su curiosidad y han colocado cortinas de humo para que no descubran sus cualidades, capacidades y potencialidades. Los hermanos son la psiquis de las mujeres, su empoderamiento emocional para enfrentar al depredador y librar los obstáculos para sobrevivir.

En otro cuento, llamado Vasalisa, el don es una muñeca que regala una madre moribunda a su pequeña hija: "Yo ya no voy a estar para cuidarte y protegerte, guarda esta muñeca en el bolsillo de tu falda y, cada vez que te sientas perdida o en peligro, aprieta la mano de la muñeca y te ayudará". Meses después de la muerte de la madre, el padre se vuelve a casar con una mujer que tiene dos hijas, quienes esclavizan a Vasalisa y para deshacerse de ella la mandan, en medio de la oscuridad de la noche a través del bosque, a buscar leña para prender fuego en la casa. La idea es que la bruja Baba Yagá, quien habita en el bosque, se coma a la niña. Cuando efectivamente Vasalisa se pierde, la bruja la encuentra y la lleva para su casa. La llena de tareas: darle el maíz a las gallinas y recoger los huevos, preparar la comida, barrer, lavar la ropa y en fin....la llenaba de tantos oficios para que no pudiera cumplir y se la pudiera comer. Cuando la bruja llegaba en la noche a la casa, encontraba todo hecho y Vasalisa estaba durmiendo; de manera que no se la podía comer porque era "obediente" cuando era la muñeca la que hacia todo el quehacer. Qué significa la muñeca? Es la psiquis de la niña, la confianza en sus capacidades, creer en sí misma. La bruja significa ese ser horrible, de risa estruendosa que prepara brebajes y se come los niños desobedientes pero tiene conocimiento y ética; como arquetipo de una historia es la que tiene la información, conoce las cualidades de las hierbas para hacer amarres, evitar o interrumpir embarazos. La madrastra y las hermanastras 
corresponden a arquetipos de mujeres malas, ambiciosas y que representan una amenaza para las mujeres. En esta historia, el depredador no es la bruja sino la madrastra y las hermanastras.

Así, los dones son medios personalizados de ejercer el poder sobre las mujeres vulnerables al poder de los hombres. Significa circularlas como mercancías o bienes simbólicos en la economía masculina. El matrimonio significa obtener sus servicios domésticos y la construcción de una familia. La cultura nos vende la maternidad como la realización plena y sagrada de las mujeres pero en realidad, como sostiene Silvia Federicci (2010), las mujeres son las encargadas de parir la mano de obra para el mantenimiento y reproducción del sistema capitalista. Nos vendieron una idea de maternidad romántica, dulce y tierna pero en realidad es control sobre el cuerpo y la sexualidad de las mujeres. Quienes han legislado y castigado el aborto son los hombres de ahí los movimientos feministas que protestan y marchan exigiendo la despenalización de la interrupción del embarazo. Así,

la violencia simbólica se ejerce mediante las mismas formas simbólicas adoptadas por los dominados para interpretar el mundo, lo que implica simultáneamente conocimiento y desconocimiento (méconnaissance) de su carácter de violencia o imposición. Al aceptar un conjunto de presupuestos fundamentales, prerreflexivos, implícitos en la práctica, los agentes sociales actúan como si el universo social fuese algo natural, ya que las estructuras cognitivas que aplican para interpretar el mundo nacen de las mismas estructuras de este mundo (Fernández, 2005, p.15).

Junto con los dones está la deuda, que perdura en el tiempo, y se establece entre un dominador perceptor y una donante de tiempo, afecto, cuidado, reproducción a cambio de sostenimiento económico y presencia social. De manera que "dar es poseer a la otra y esto se encuentra oculto en actos públicos de generosidad. La violencia simbólica se traduce en relaciones de dominación y sumisión y en relaciones afectivas en las cuales el poder se confunde con carisma. La dominación se disfraza pues la víctima reconoce que tiene una deuda con el dominador, lo cual se convierte en agradecimiento e incondicionalidad con quien provee el sustento y es el jefe del hogar. Esto se llama amor y configura una relación de reciprocidad entre el dominador y la dominada. Bourdieu en su obra La dominación masculina explica que la relación sexual y la violación constituyen una relación social de dominación que parte del imaginario dicotómico: masculino-activo, femenino: pasivo y este esquema de pensamiento crea, organiza, manifiesta y se representa en deseo masculino por el cuerpo femenino a ser poseído, mientras que el deseo de la mujer es subordinación y reconocimiento erotizado de la dominación masculina. "Cuando los dominados aplican a lo que les domina unos esquemas que son el producto de la dominación o, en otras palabras, cuando sus pensamientos y sus percepciones están estructurados de acuerdo con las propias estructuras de la relación de dominación que se les ha impuesto, sus actos de conocimiento son, inevitablemente, unos actos de reconocimiento, de sumisión" (Bourdieu, 2007, p. 26).

Sin embargo, Bourdieu deja claro que los privilegios masculinos son una trampa pues la virilidad se debe demostrar públicamente, lo cual constituye un desgaste físico y emocional, mientras que las mujeres tienen un honor negativo centrado en la virginidad y la fidelidad. "La virilidad, entendida como capacidad reproductora, sexual y social, pero también como aptitud para el combate y para el ejercicio de la violencia (en la venganza sobre todo), es fundamentalmente una carga. 
De manera que el verdadero hombre es el que defiende su honor "buscando la gloria y la distinción en la esfera pública". Los valores masculinos están fincados en "los miedos y las angustias que suscita la feminidad: débiles en cuanto que encarnaciones de la vulnerabilidad del honor (...), siempre expuestas a la ofensa, las mujeres también están provistas de todas las armas de la debilidad. Como la astucia diabólica y la magia" (Bourdieu, 2007, p. 68). Además, la valentía se basa en la cobardía y lo demuestran actos como matar, torturar o violar, la voluntad de dominación, de explotación o de opresión, se ha apoyado en el temor de excluirse del mundo de los hombres fuertes, de los llamados a veces duros porque son duros respecto a su propio sufrimiento y sobre todo respecto al sufrimiento de los demás -asesinos, torturadores y jefecillos de todas las dictaduras y de todas las instituciones totalitarias, incluso las más corrientes, como las cárceles, los cuarteles o los internados- (...), "la virilidad es un concepto eminentemente relacional, construido ante y para los restantes hombres y contra la feminidad, en una especie de miedo de lo femenino, y en primer lugar en sí mismo" (Bourdieu, 2007, p. 70,71). Interesante aporte de Bourdieu porque el sistema patriarcal tampoco le sirve al género masculino pues también a ellos les cobra muy caros sus privilegios; demasiada exigencia para no ser felices. En cuanto que el patriarcalismo va de la mano con el capitalismo, cada vez los hombres son más vulnerables a la volatilidad financiera y al desempleo, factores estos que aumentan las estadísticas de violencia hacia las mujeres, hasta llegar al feminicidio, pues se ve lesionado el ego masculino como actor económico.

Las amenazas que circulan como imaginarios colectivos en una sociedad jerarquizada, educan a las mujeres en aceptar como evidentes, naturales y obvias normas de sometimiento que se graban en los cuerpos. Por eso, la llamada por Bourdieu "vocación" tiene como fin "producir encuentros armoniosos entre las disposiciones y posiciones que hacen que las víctimas de la dominación psicológica puedan realizar las tareas subalternas o subordinadas atribuidas a sus virtudes de sumisión, amabilidad, docilidad, entrega y abnegación” (Bourdieu, 2007, p. 77). Se trata pues del amor romántico, la maternidad y las relaciones laborales. En Colombia llamó la atención de la gente el saber que había mujeres en la guerrilla y cuando algún periodista lograba entrevistar a alguna contaba que estaban encargadas de preparar la comida y ser las amantes de los dirigentes. ¿Es este un orden natural imposible de cambiar? Se trata de construcciones mentales que configuran visiones del mundo desde el ser masculino dominador, legitimadas con la complicidad de las mujeres que aceptan inconsciente y hasta conscientemente su inferioridad y obediencia. Al ser imaginarios colectivos arraigados en la memoria colectiva habría que proponer, para disminuir significativamente la violencia contra la mujeres y el feminicidio, cambiar esos imaginarios ¿cómo? A través de una educación para la igualdad y la justicia de género basada en el reconocimiento. Esto conllevaría un proceso de concientización que necesitaría de los medios de comunicación, las redes sociales y la crianza. Por ejemplo, en la telenovela tradicional mexicana, las mujeres estaban siempre en la casa cuidadas y protegidas por el padre quien, además, salvaguardaba el honor de su hija. Ellas siempre muy arregladas exclusivamente esperando el príncipe azul para casarse y formar una familia. La telenovela colombiana de los noventas transformó el rol de las mujeres colocándolas como empresarias y los hombres eran los secretarios. Las audiencias se sintonizan con esos nuevos imaginarios construidos a través de los medios de comunicación y comienzan a ver a las mujeres como capaces e iguales. Esto se va reflejando en las prácticas cotidianas y en el lenguaje, de manera que así como se naturalizó la violencia, se puede naturalizar un imaginario de reconocimiento e igualdad entre hombres y mujeres para contribuir a la disminución significativa de la 
violencia contra las mujeres y el feminicidio. Los cambios son lentos pero hay mucho por hacer para lograrlos.

\section{Referencias bibliográficas}

Amorós, C. (2000); Tiempo de feminismo: sobre feminismo, proyecto ilustrado y postmodernidad, Ediciones Cátedra, Universitat de Valencia, Instituto de la Mujer.

Barthes, R. (2011). El placer del texto. México: Siglo XXI ed.

Bernal M., J.A. (2013). La mujer-objeto de intercambios en las sociedades Primitivas: Una lectura entre Pateman, Irigaray y Baudrillard. Universidad Pedagógica Nacional. Revista Grafia Vol. 10 N² 2 - julio-diciembre 2013 - pp. 143-157 - ISSN 1692-6250.

Butler, J. (2001). El género en disputa. El feminismo y la subversión de la identidad. México: Paidós.

Butler, J. (2010). Marcos de guerra. Las vidas lloradas. México: Paidós.

Bourdieu, P., (1997). Razones prácticas sobre la teoría de la acción. Barcelona: Anagrama.

Bourdieu, P., (2007). La dominación masculina. Barcelona: Anagrama.

Caputi, J y Diana E.H. Russell (2006); Feminicidio, sexismo terrorista contra mujeres, en J. Radford y D. E. H. Russell: Feminicidio. La politica del asesinato de las mujeres; Centro de Investigaciones Interdisciplinarias en Ciencias y Humanidades, Universidad Nacional Autónoma de México DF.

Collignon, M. (2010). La vida amorosa, sexual y familiar en México. México: ITESO.

Flores M., J.A. (2011). Violencias en la carne, emociones y "cuerpos" domésticos en Veracruz, México. En Segovia, Y., y Nates, B. (2011). Venezuela: Universidad de los Andes.

Kristeva, J. (2003). Poderes de la Perversión. México: Siglo XXI Editores.

Le Breton, D. (2002). La sociología del cuerpo (1 $1^{\mathrm{a}}$. ed.). Buenos Aires: Nueva Visión.

Pérez M.L y A. Larrondo (2016) Derechos Humanos en Crisis. Feminicidio en el estado de Puebla. Informe 2010-2014, Colección Cuadernos de Investigación, Universidad Iberoamericana, Puebla, México.

Segato, Laura Rita (2014). Las nuevas formas de la guerra y el cuerpo de las mujeres. Puebla, México, Pez en el árbol.

Segovia, J., y Nates, B. (2011). Territorios, identidades y violencias. Universidad de los Andes, Venezuela, y Universidad de Caldas, Colombia. 


\section{Referencias electrónicas}

Biblioteca Nacional. Expedición botánica. Consultado el 6 de junio de 2016 en: http:/ / www.bibliotecanacional.gov.co/blogs/expedicionbotanica/2010/12/20/elencierro-rito-de-paso-en-la-cultura-wayuu/ http://wvw.nacion.com/dominical/2003/junio/15/dominical10.html

La Nación: Revista dominical. Las mártires de Ciudad Juárez. En línea: http://wvw.nacion.com/dominical/2003/junio/15/dominical10.html. Consultado el 30 de marzo de 2017.

La masacre de Acteal. Sitio web de la sociedad civil Las abejas. En línea http://acteal.blogspot.mx/p/la-masacre-de-acteal.html. Consultado el 30 de marzo de 2017.

Nuestras hijas de regreso a casa. Sitio web de las madres cuyas hijas fueron asesinadas en Ciudad Juárez. https://nuestrashijasderegresoacasa.blogspot.com

Daniel Berehulak, Las mujeres de Atenco. The new York Times. En linea: https://www.nytimes.com/es/interactive/las-mujeres-de-atenco/. Consultado el 30 e marzo de 2017.

Martínez, A. (2010). REFLEXIONES EN TORNO AL CONCEPTO DE CLASE SOCIAL Pierre Bourdieu y el espacio social pluridimensional. Astrolabio, (2). Recuperado a partir de https://revistas.unc.edu.ar/index.php/astrolabio/article/view/ 176

Videografia

Disney, A.E., Hgan, P., Reticker, G. (2012). Pray the devil back to hell. Liberia [video]. En Women, War \& Peace. 